\title{
'We need to get the fundamentals right'
}

\author{
Professor lain Chapple 1 joined forces with the Johnson \& Johnson team to help create The OH! Challenge and, \\ now that the results are in, shares his view of what it all means with $B D J$ readers.
}

\begin{abstract}
T aunched at this year's British Dental Conference, The $\mathrm{OH}$ ! Challenge was created to test dental healthcare professionals' (DHCPs') oral health knowledge and has highlighted some interesting gaps, including:

- $46 \%$ did not know that gingivitis and periodontitis are a continuum of the same inflammatory disease

- Only $44 \%$ knew the updated BPE guidelines for code 3 sextants

- $22 \%$ of respondents did not know what a BPE code 1 meant.
\end{abstract}

A total of 464 DHCPs took part in the survey, with an overall average score of $51 \%$ amongst all participants.

\section{Talking points}

What was your motivation for becoming involved with The $\mathrm{OH}$ ! Challenge?

Iain: In large part, it was because I am keen to acquire objective data on DHCP' understanding of how the ever-changing scientific evidence base and policies translate into everyday practice. I was intrigued as to what The $\mathrm{OH}$ ! Challenge might reveal.

\section{What struck you about the results?}

Iain: I was very surprised at the lack of understanding of what a BPE code 1 means, as well as the low number of respondents who knew about the relatively recent changes to the British Society of
Periodontology (BSP) guidelines. That is a real worry. On the other hand, it was pleasing to learn that the vast majority of DHCPs know the importance of the plaque biofilm, and that disrupting it is a key aspect of oral health.

Why do you suppose almost half of respondents didn't know that gingivitis and periodontitis are a continuum of the same inflammatory disease?

Iain: It wasn't really until 2005 that the conclusion was reached that gingivitis and periodontitis are a continuum of the same disease. That's our fault for not getting the message out there as much as dentists not looking for it. I think one of the great things about The $\mathrm{OH}$ ! Challenge is that you will be able to feed back what the areas are that practitioners need to focus on to update their knowledge.

In dentistry, we have four main oral health conditions affecting the majority of the population: caries, periodontal disease, non-carious tooth surface loss and mucosal diseases. It's a narrow field, and we need to get the fundamentals right so that every DHCP is recognising potential problems before they develop, as in the case of gingivitis, which may lead to periodontitis and tooth loss.

What do you think could be done differently, to help DHCPs stay ahead of the continuing education curve?

Iain: DHCPs need to be able to access key information on changes in policy and clinical recommendations. That's partly the responsibility of the education providers, but the buck has to stop with the dental professional. So, I would say that DHCPs need to be proactive in their pursuit of appropriate, ongoing education opportunities, and should be pushing for more clinically relevant and accessible CPD from training organisations.

Do you have any suggestions as to how busy DHCPs might be able to balance the demands of everyday practice with the ongoing requirements to stay well-informed?

Iain: I think many of us need to embrace a more holistic approach in our careers. It's easy for some aspects to fall by the wayside, given the day-to-day need to see patients and run the business. But, really, we need to consider that we might be able to perform some of those tasks in a quicker and smarter manner, through taking time out for further education. It's not unlike the adage of spending money to save money. We could conceivably spend time in education to save time in practice!

Visit www.listerineprofessional.co.uk to see The $\mathrm{OH}$ ! Challenge in more detail and to follow the supporting programme of evidence-based content that will be released in instalments over the coming months.

1. Iain Chapple is Professor of Periodontology, Consultant in Restorative Dentistry, and Head of the School of Dentistry at the University of Birmingham.

\section{Honours, awards, appointments}

25th anniversary awards 2017

FGDP(UK) has announced the winners of three prizes celebrating the achievements of the profession in the Faculty's 25th anniversary year:

Foundation Dentist of the Year: Claire Culverwell. Claire was originally a dental nurse, before qualifying as a dental hygienist and then a dentist.

Highly commended: Harry McKenzie.
Community Dentist of the Year: Jason Wong, who has championed oral health in his local community via local groups, boards and committees, in addition to an active profile on social media.

Dean's Award: Dentaid, for their support of The Real Junk Project, a practice in Dewsbury offering 'pay what you can afford' dentistry. 